\title{
Embossment and its significance approach to practicing Contemporary Art
}

\author{
Tikendra Kumar Sahu \\ Assistant Professor, Department of Fine Arts, Amity University, Noida \\ Email: tikendra4sahu@gmail.com
}

\begin{abstract}
Embossing is the art term of any process - e.g. casting, chasing, stamping, carving or molding- designed to make a pattern or figurative composition stand out in relief. The present paper discusses the contemporary practices of embossing by different Indian artists under three broad categories: Pressing, Carving and Punching. This will discuss the artworks of the artists for exploring the motivational aspects and for examining the development of visual language. All the primary case studies of were evidently researched by having a direct observation of their practices through interviews and by examining primary and secondary textual sources moderated by their artistic process as the contemporary modernist approaches.
\end{abstract}

Keywords: Contemporary art, Embossment, Embossing art practices, Contemporary embossment, Indian Art

Embossing is the art term of any process - e.g. casting, chasing, stamping, carving or moldingdesigned to make a pattern or figurative composition stand out in relief. Sometimes also used as a synonym for 'repousse', (the French word for 'pushed back'): Metal hammered into a relief design from the back (Lucie-Smith, 2003). Embossing- the term is also used in printmaking to describe an intentional relief produced by stamping or molding. It is derived from 'boss' (Middle English. boce, bose), meaning a rounded protrusion (Turner, 1996). A raised design or symbol that has been embossed by an impression produced by pressure or printing while relief is a type of artwork in which shapes or figures protrude from a flat background. The word relief is derived from the Latin verb 'relievo', which means to rise.

Relief is a sculpture oriented technique and the sculpted components remain attached to a solid background of the same material in which the material has been raised above the background plane. Various materials can be used for relief making, for example- metal, clay, plaster stucco, ceramic, or paper-mâché the form can be developed through to an added or raised up from the background. Bronze reliefs are made by Modeling, molding, waxing, heating, and casting. The lost wax process is also called the waste wax casting because the mold is destroyed to remove the cast item. This hollow wax replica of the original model is removed from the mold. The model-maker may reprocess the mold to make several replicas, limited only by the strength of the mold.

Embossing is based on the positive and negative surface which is often called as male and female die where the artist decides the final outcome with raise in relief surface. The curved surface is called mold or die or negative and printed image or casted image imparts the final result of print or cast or positive. We can interpret mark, mold or decorate a surface with a raised

(C) AesthetixMS 2018. This Open Access article is published under a Creative Commons Attribution Non-Commercial 4.0 International License (http://creativecommons.org/licenses/by-nc/4.0/), which permits non-commercial re-use, distribution, and reproduction in any medium, provided the original work is properly cited. For citation use the DOI. For commercial re-use, please contact editor@chitrolekha.com 
design or symbol as raise surface result that made by process of embossing. In general, embossing can be achieved through the following process; it depends upon the quality of result expected with a specific medium and material by reaching the purpose of making art because, in art material, it is a matter of a concern when an artist chooses specified contextual justifications. In this paper, the researcher will discuss the contextual frameworks on embossment under the process- pressing, carving, punching, and casting with the example of works by artists.

\section{Pressing}

Embossing is a 'single-sided' effect. With the fibers being pushed up into the embossing matrix from the back it will always show through. Also, as two parts of the mold come together, very fine lines need to be avoided as they simply don't work (Design Dynamic Print, 2017). Embossing makes elegant result when an artist uses depths and styles to approach aesthetic value in the final embossed surface. When depth and raised surface is increased, the embossed works will appear more appealing and attractive with a sense of composition in arts and design (McIntosh Embossing, 2017). Krishna Reddy is the most outstanding innovative experimenter in the art of color viscosity printmaking. He speaks of human urge to gain knowledge from the immense source of nature and the artist's desire to experience and penetrate into creativity itself. Stanly William Hayter's prints produced brilliant color but they were too technical; his works speak of pure form, color and automatism. In contrast, Krishna builds up his plate almost as it is sculpted out.

Krishna Reddy's images manifest themselves in the form of embossed lines and impregnated colors, both of which are variegated and subtle. A theme drawn from nature has been etched vividly and presented with all the nuances that the medium is capable of rendering and with much that was inspiring in the natural manifestation (Lalit Kala Contemporary-34, 1987).

Krishna converses his feeling for the seminal forces around him, the natural and the elemental, the human and the spiritual. That the elemental is associated and is consonant with the spiritual is implied in his work. Krishna is not bothered with events or stories, with the intensity or the storyline content of subject matter; for him, more essential than a subject is the life dynamism that binds the Universe together.

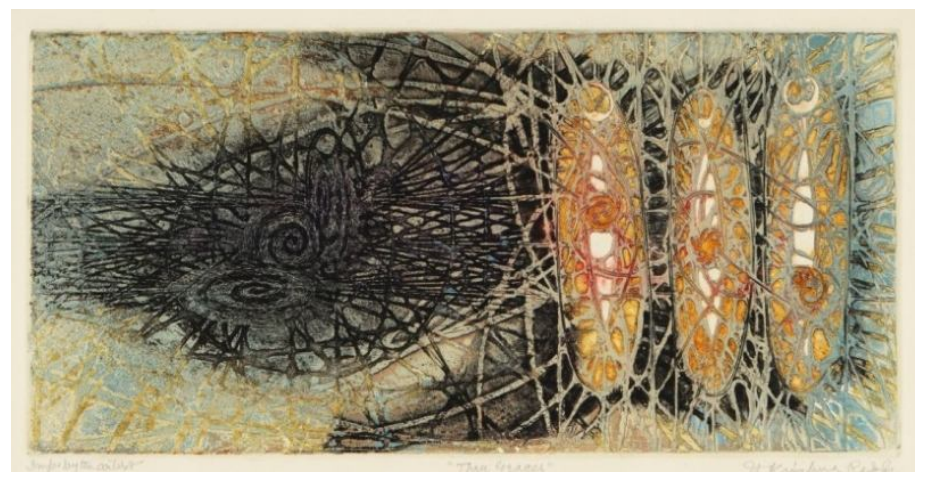

Figure 1: Krishna Reddy, Three Graces, Mixed color intaglio on paper, 1958, Size- 9.33 in. (23.70 cm.) (Height) by 19.25 in. (48.90 cm.) (width) retrieved on 15 May 2018 from https://www.blouinartsalesindex.com/auctions/KrishnaReddy-6979299/Three-Graces-1958

Krishna Reddy says, 
"As we want to know ourselves and there is a development in creativity, revelation, and learning. The art-making is a learning process and a creative process, this is real joy of life to find enlightenment, live, discover, understand and learn." (Sengupta, 2006)

He says

"We stand between the immense cosmos and the unfathomable universe within us. If we pause for a moment and watch these great mysteries, we are filled with awe and wonder. There is an urge in us to discover and learn what lies behind these mysteries, the hidden reality that is the very source of life. Just as our bodies want nourishment, our minds want to know." (Reddy, Krishna, 1988)

The intricacy of techniques and materials in printmaking can lend themselves to a compulsive development of technique. The commercial influence is a force and directly opposes creative experimentation. Techniques are obtainable to us as proven formulas to be tracked. If we follow the dictates of formula we lose ingenuity essential to building a meaningful image. If we do not question the techniques, they become our authorities. The artist will get most pleasure and contentment if the works are valued for their true conceptual orientations, without giving the pseudo-significance to any other external value.

Multi-Level embossing is the image area raised to multiple levels having different depths. This gives the embossed image texture and added relief and makes it all the more interesting. The hundreds of layers overlap on it, not deliberately but because of the technique. So this was subjectively needed to be explored in such means, and this is the way of functioning in works by R. Balla.

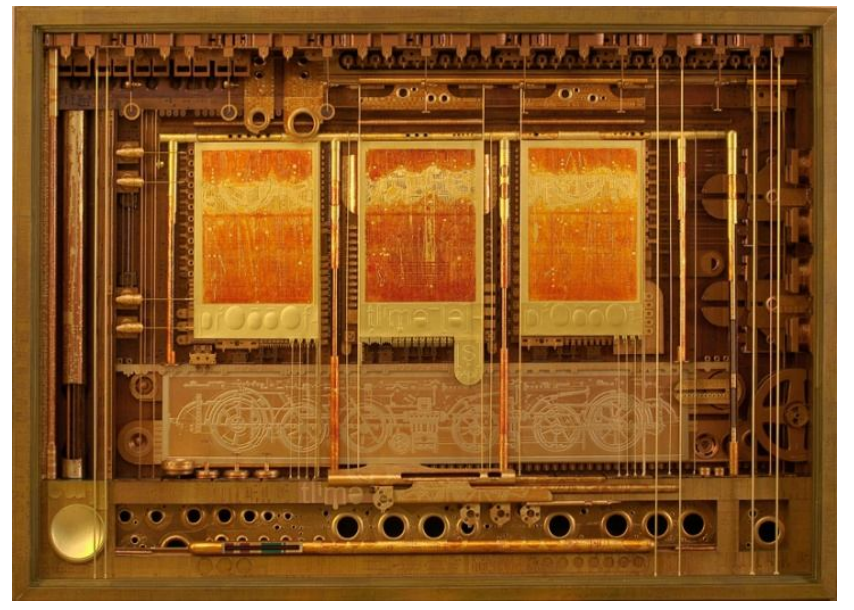

Figure 2: R Balla, Dynamism in the mobility and movement-stained container on the wheel (copperix), construction built in the box Processed - 1995 - 2008, 40" x 62" x 8", Retrieved July 20, 2016, from R Balla by Sahu T.K.

This is an effort to visualize the relativistic nature of 'time' by pursuing the expanding nature of 'time' along with motion. Time is reckoned by noting the intervals that occur by the motion of visible or invisible material things. It is in consequence of this that space and time are welded together. Every material thing can also have an absolute character, provided we choose an appropriate reference frame to consider with. So, we can agree with the materialistic view that time is solidly linked to the motion of matter. Balla says

"The precise concept initiates the whole understanding of movement, motion, and momentum existing altogether with space-time simultaneously called the "qualitative process of motion...In the search for understanding of the phenomenon known as 'life', 
and with the understanding that 'life' can never be located in the constituents of any living form or organism, the only and inevitable criterion is the 'holistic perception', the perception that of a human form is the realization of the life as a whole. (Baala, 2018)

A sculptured emboss actually refers to a hand-tooled process. It is made of a photograph or a drawing with various levels of depth to make the image appear realistic and multidimensional. An artist needs to take the responsibility and create responsible works of art for the society that is the motivation Balla is adopting from the Indian orientation and implementing into his/her life.
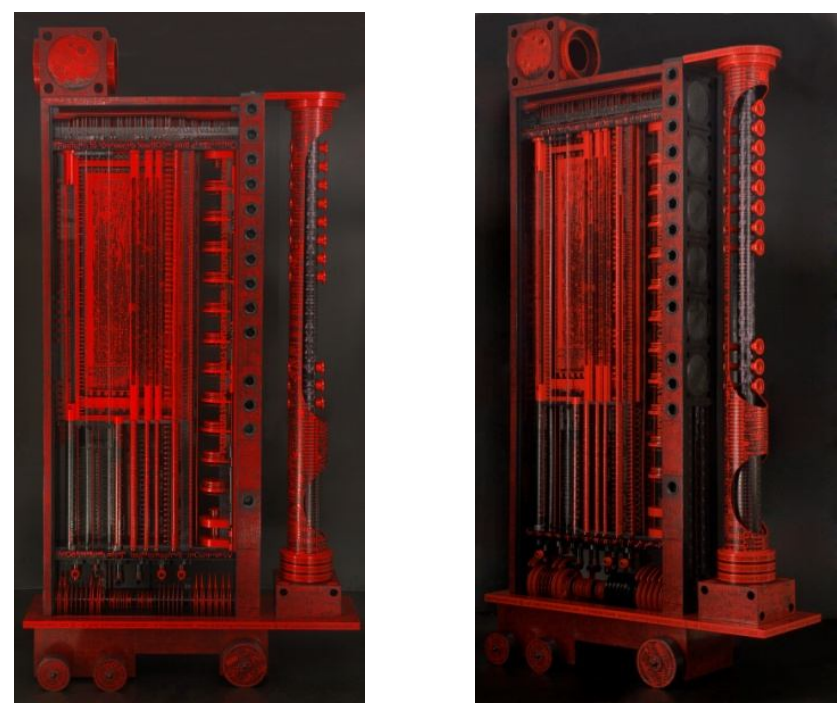

Figure 3: R Balla, Organic intelligence, Pulse of artificiality and nature, Processed 1999 - 2009, a construction built in and out of the box, Dimension - 120" x 6o" x 24" Retrieved Apr 20, 2017, from R Balla

Almost all the practices and especially all the scientific practices of the society, as of today, pose the question, 'Whether human belongs to nature or nature belongs to the human?' Human can never survive even a moment without nature around, which is being consistently utilized, enjoyed, explored, amazed, protected, exploited, destructed and destroyed (Baala, 2018). The knowledge and practices of the human society, 'artificial' could be specified as something which is invented by human as the product of ignorance coupled with artificial intelligence. Artificiality is not coupled with the material; it is a kind of mental state which is against nature, the realization of 'self' and on the human society as a whole towards 'existence' and true living.

\section{Carving}

Carving is sunk below the level of the surrounding surface and contained within a sharply incised contour line that frames it with a powerful line of shadow. The surrounding surface remains untouched, with no projections. Sunken relief carving is found almost exclusively in ancient Egyptian art, stone carving from the flat surface is the appropriate example for the relief. Craving is the final stage of the works of art so that carved surface itself become most important and interplay significantly both positive and negative space together.

According to the process, embossing can be achieved by using one or more processes. Only carving alone cannot be put in the category of embossing thus it can be a stage of the process of embossments and the print or cast on the created surface is taken as a die. I would like to clarify about the relief and embossed image; when a person is very clear about the final 
outcome and results, it will be distinguished technically and dependent upon the intention of the artist.
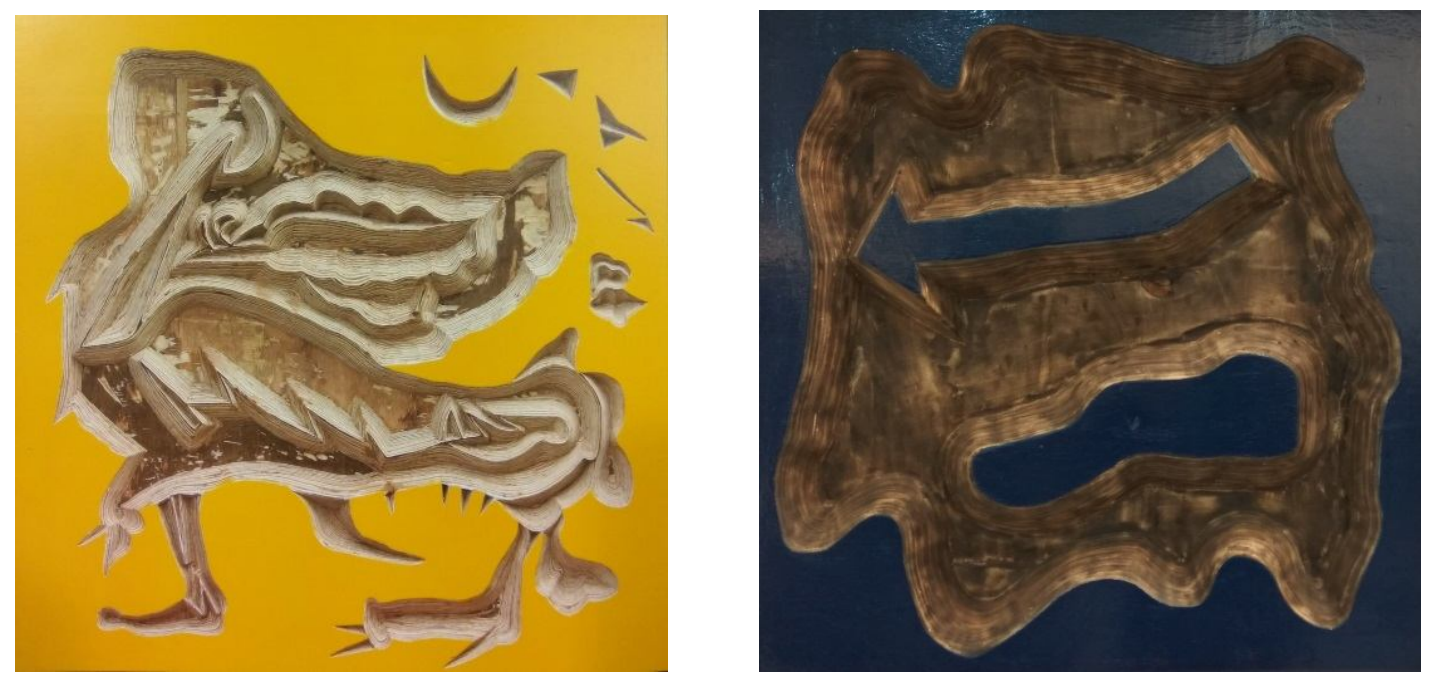

Figure 4: Jeram Patel (left) Untitled, acrylic on wood, 124 x 124 x 5 cms, 2008, Figure 5: (right) Untitled, acrylic on wood, 124 x 124 x 5 cms, 2008, Retrieved Apr 20, 2017, from Exhibition Catalogue Mirrored Reality with Cognitive Images by Art Home, Vadodara, 2008

Simplicity becomes the hallmark of Jeyram's creations; the works are simple, direct, in their bare minimum entities, yet are multifarious in their visual appeal and intent. (Shukla, 20o8). A magnetizing surreal world is created by Jeyram Patel in his landscape, slowly changing with his positive areas of the work plywood contrast created away from the submissive surface of the area with glowing glossy shiny steel or paint. The landscape of life's drama is transient; reflecting on the diffused light of these reflections would have even more elucidations of the art.

Myriad reflections of self and surroundings move and change with every twist and turn; these shifts and changes were reflected on the polished surface of the stainless steel that encased the carved, engraved and semi-burnt amalgamated plywood sculptures of Jeyram Patel (Chandra, 2009). There are several artists practicing by carving the wood surface and painting to create relief as a final result of works of art. For instance artists -- Alex Mathew, Chippa Sudhakar, Dhreej Choudhury, Piraji Sagara and many more have used similar relief works to express artistic concern. The purpose of creating embossing works according to the transformative process from negative to the positive but in relief, merely carving stands out as the final justification of the work.

\section{Punching}

The most substantial stimulus of P.V. Janaki Ram has been the South Indian temple, with its wealth of pillars, metal door reliefs, icon and the polished covers in the repousse technique, called Kavachas which were fitted on to stone or wooden deities and mounts.

Janakiram does not let any pre-conditioned material inflict itself on him and limit his ideas. He uses fresh copper or iron sheet which he beats and fashions at will resorting to bracing or welding bits of metal, metal tape, nail and wire for special effects. His compositions drawn from the pantheon of popular deities and images inspired by a wealth of folk images are not beyond the understanding of the common man (Janakiram, 1974). 


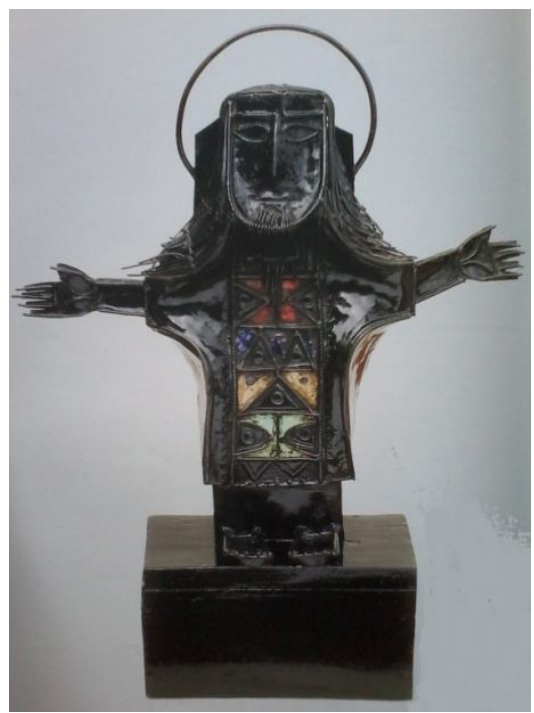

Figure 6: P.V. Jankiram, Christ, Oxidized copper and enamel, 50.8x 43.3cm. Retrieved June 22, 2013 from Marg, A Magazine of the Arts, the Marg Foundation, 2010, Vol. No. 62/4, pp.123

Clarifying sculpture extensively of the more subtle possibilities of illusionist identification, he cut into the continuities of extension and outline that P.V. Janakiram rested on; broke up further into smaller distributions of the same elements, making up on the whole, articulate, calligraphic patterns of quite some complexity and detail (Josef, 1987). In Janakiram's sculpture, it is felt in its rarified sheet-thin body and in what might appear as decorative details in his later work. Whereas it functions to disperse in S. Nanadagopal's work into open, free-standing patterns of points, angles, curls, edges, and planes.

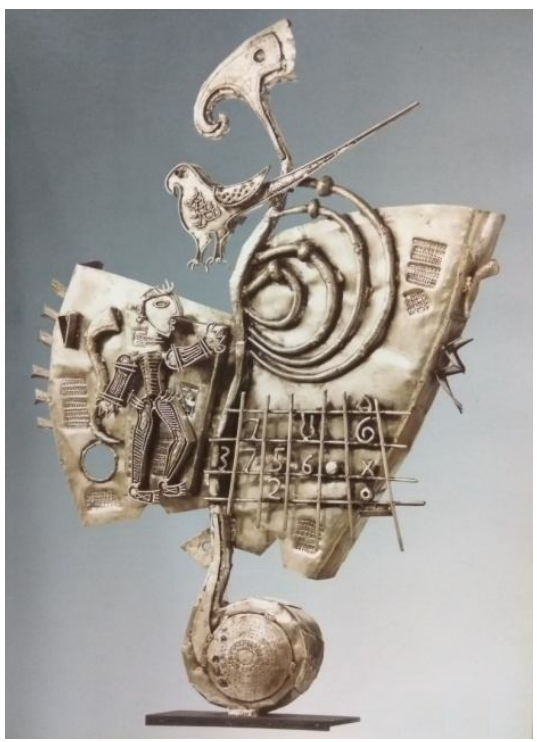

Figure 7: Nandagopal, Landscape-I, silver plated copper and brass, 5’ x 4’ x 8”- Retrieved March o3, 2017 from Gallery Time \& Space Bangalore, Vignettes-Passages-Parables, The Madras Movement Published by Nandagopal, 2010

Deep etch is in a sense, a deep open bite, although, as a rule, the bitter areas are generally more definite and condensed. It is the abrupt wall of metal, enclosing the corroded area, that characterizes the really deep etch, and it is this wall or edge that holds the main body of ink, enriching both plate and print surface. As deeper the bite, the stronger and darker each embossed area of deposited ink will be on the print (Chamberlain, 1972). A deeply etched plate can be 
printed in relief, intaglio or both together. While using the intaglio method, actual depth appeared with a greater illusion of depth, and the range of tone and color. Most of the blocks are extremely adaptable and by experimenting and employing the techniques with a large variety of prints is possible from a single block overprints used by reversal and subtractive process. Part can be cut away or glued on; depending on the use of a different block or technique combinations of positions and colors will give a variety of prints (Capon, 1973). SG Vasudev's copper work seems to flow like poetry. It spurts into the life of imagination, dream, fantasy and the common relationship between human and nature in order of Shiva-Shakti and ever spacious speaking tree. This embraces the mystic, physiological and spiritual message into within the forms of creative exploration (Pillai, 2003).
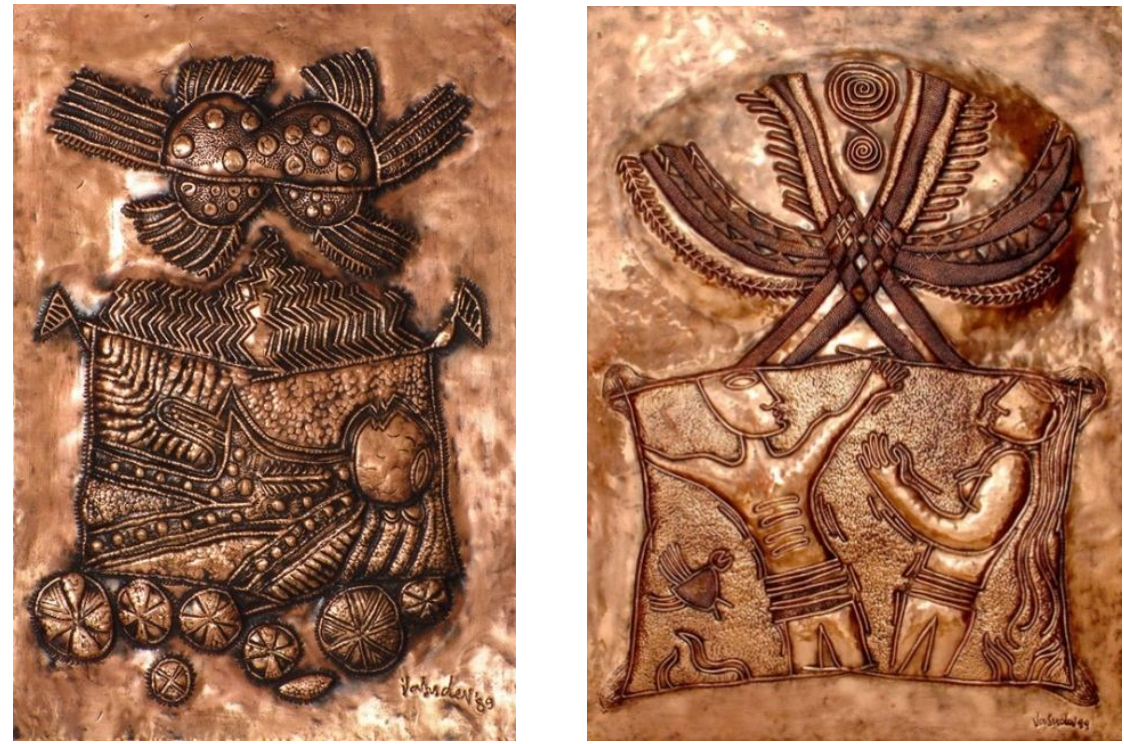

Left Figure 8: Chariot, Copper Embossed, 32x47 cms 1989 / Right Figure 9: He \& She, Copper Embossed, $90 x 118$ cms 1999, Retrieved 22 June 2016 from Vriksha- The art and times of S.G. Vasudev, Published by Popular Prakashan Pvt. Ltd. 2013

His copper embossing works surpass because the medium itself is turned in to a dramatic spectacle, according to the light conditions changes can be experienced in the works of the metal surface. Creative abilities can be justified by precise care by the designer to make appropriate, comfortable and aesthetically pleasing to others; the sensibilities imparted with creative practices by an artist.

\section{Casting}

Somnath Hore introduced the paper pulp casting on the texture created with wax and found objects for the series of works titled "Wound". The subject depicted the human suffering and riots of Bengal and Bangladesh. His white paper Pulp done on the smooth surface of clay, like knife marks on human skin immortalizes the wound by transferring it into works (Ghose, 1977). 


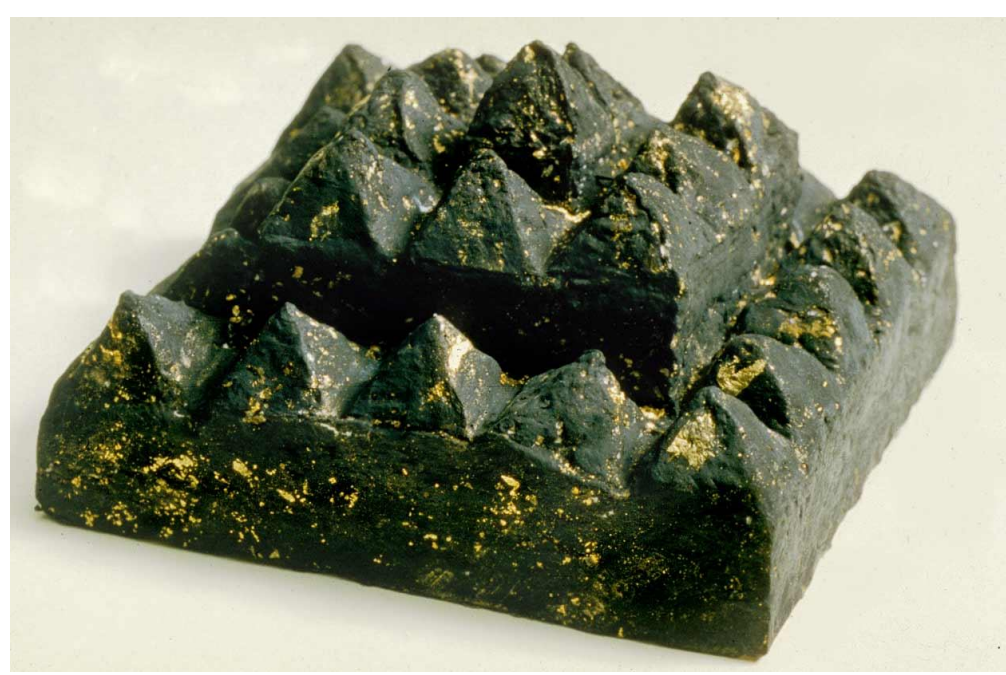

Figure 10: Zarina, Home, cast paper sculpture, 20" x 20.5” x 5", 1988 retrieved on $15^{\text {th }}$ May 2018 from http://artasiamerica.org/search/by/techniques/300053104

While the works of Zarina Hashmi are as though this language takes up refuge in a void and frames concealments within lines and barriers. The surface of cast paper sculptures was the simplest and most iconic geometry which struck the eye; minimal, dramatic and enigmatic results were more sensuously expressed. She mapped from house to the world; from personal to universal (Kimbril, 2006).

Set of sixty books was composed by Ravi Kashi for the Corporate Office of the Embassy Group Builders in Bangalore, 2013. Entire Office from reception to MD's Chamber to the dining hall, all the rooms bear Kashi's works.

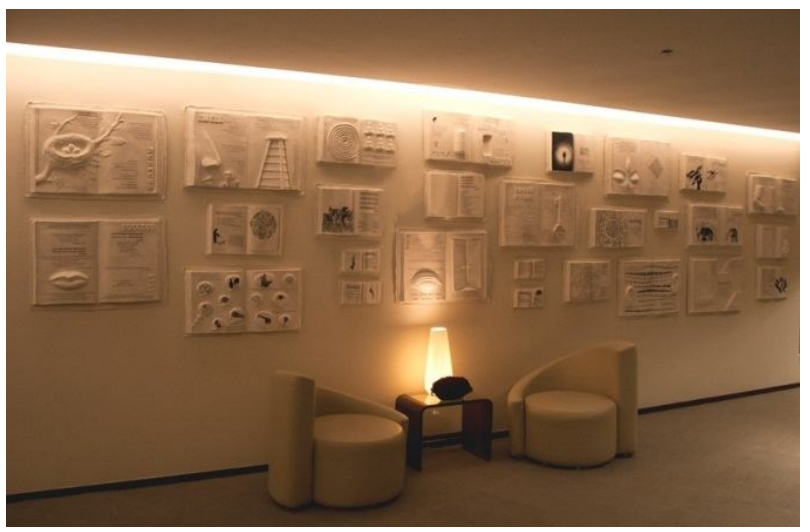

Figure 11: Ravi Kashi, Display view, Cast cotton rag pulp and photocopy transfers and ink, 2013, retrieved on 23 June 2016 from Ravi Kashi

Collecting photos, images, clippings, discarded objects, headlines, quotations and the like, which interest Kashi jotting down ideas with drawings and text, comes filtered through this secondary source, resulting in the construction of an altered reality. Ravi Kashi says, "I see myself as a witness to my times, to the ways it is being interpreted in the media and a witness to the visual culture around me". The books have been stringed together with themes related to architecture from visualizing to planning to construction and all the emotional aspects of an architectural space. 


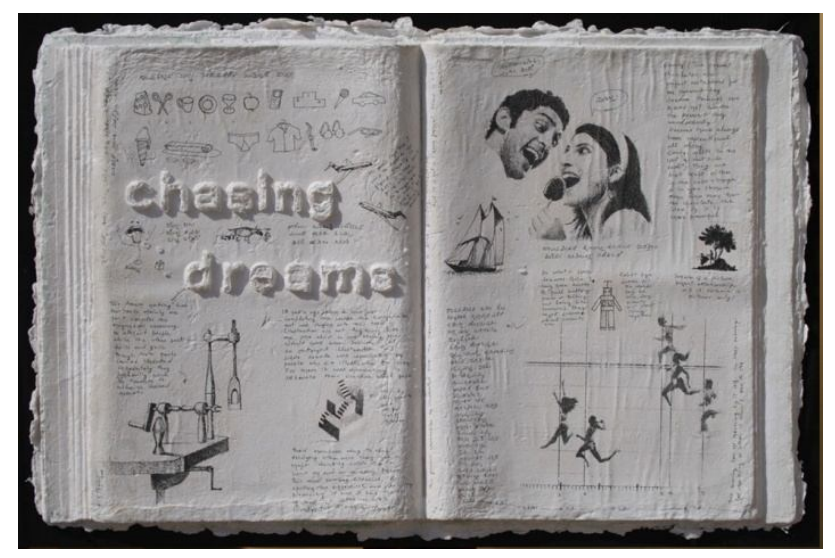

Figure 12: Ravi Kashi, Detail view. Cast in cotton rag pulp and photocopy transfers and ink,

$16 \mathrm{cms} / 6.5 ”$ x 30cms / 12” x 4cms / 1.5”, 2013, retrieved on 23 June 2016 from Ravi Kashi

When we are free from strictness, it has more possibilities. Ravi Kashi has spontaneous exploration, eclectic nature and also conviction in the modernist idea that the way something urged as an appraisal. According to Bordewekar (2013), the work on one of the Tagore's poems which said that no amount of cajoling could open a flower bud but only a ray of sun can do that, inspired K G Subramanyan to reflect that it was articulately symbolic of the process of education. Thus, he used sand cast-cement technique, worked on a large Sun image with a number of flower buds below it in various stages of blossoming (Bordewekar, 2013). In the works of Subramanyan, the most apparent things found were playfulness with great vision. Simplified approach within a complex arrangement of the things influenced by nature and overall entity with complexity makes it simple and dynamic.
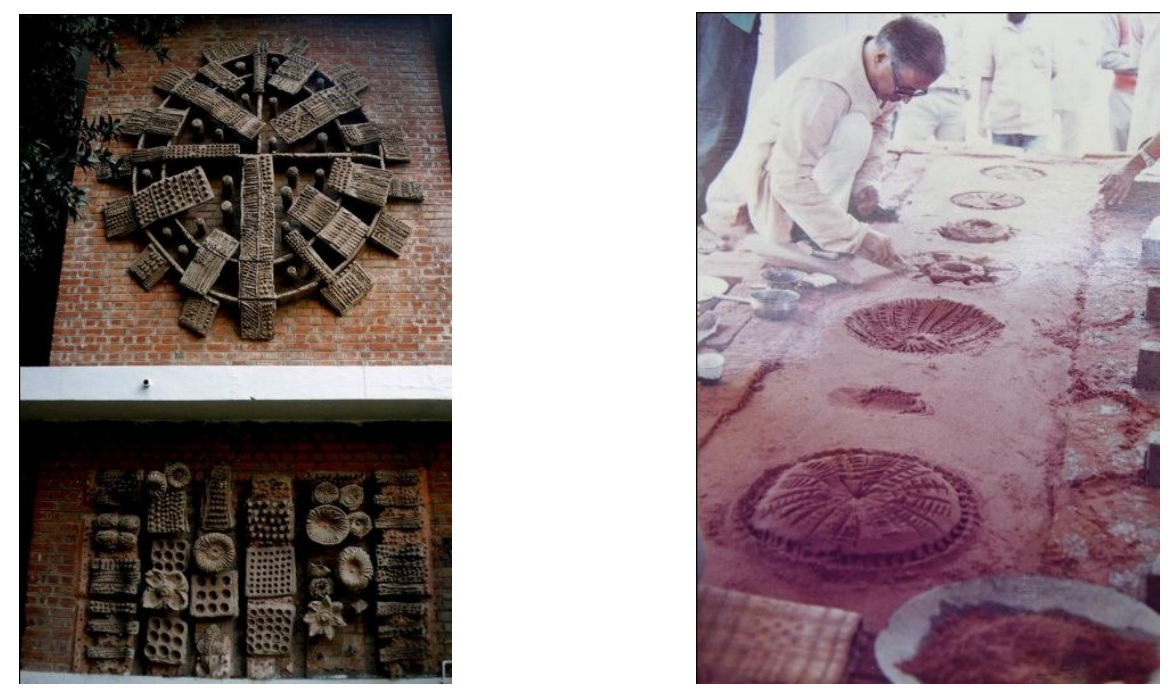

Figure 13: Mural at the Department of painting, Baroda, Upper mural 355cm x 350cm x 30cm, Lower mural $168 \mathrm{~cm} x$ 300cm x 30cm, 1964-1965/ Figure 14: Photograph of mural execution process by K G Subramayan, Retrieved 14 Jan 2015 from Art India Magazine of India, 2013, Volume XVII issue I

A sand-cast cement mural installation was accomplished by the artist K.G. Subramanyan on the Centenary Exhibition of Gandhi in Rajghat, Delhi, 1969. The works contain various impressions of relief dots and textures which allow perceiving works with sculptural qualities (Asia Art Archive, 2017). The work was part of a pavilion at Gandhi Darshan titled 'India of My 
Dreams', designed by Charles Correa and it was a kind of open courtyard measuring approximately $12 \mathrm{~m} \times 12 \mathrm{~m}$.

Dattatraya Apte recycled waste color paper from the paper factory and created his color palate. He drew inspiration from Somnath Hore, actually, he was familiar with the industrial production of paper mill and then saw the artist's final work of art Wound Series. Understanding the material, techniques, and application is an important aspect as well as for creating the idea through expression.

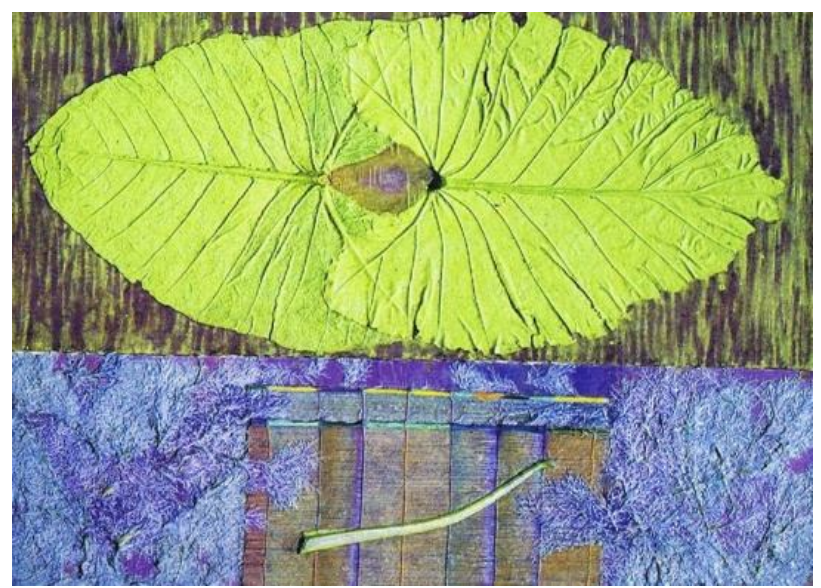

Figure 25: Dattatraya Apte, Dyed and hand colored paper pulp cast, 20" x 21", 2006, retrieved on $12^{\text {th }}$ May 2017 from http://dattatrayaapte.com/big/pulp/pulp-cast-o68.jpg,

The flight of imagination of the artist believes in the synthesis, searching and working towards a newer language for his/her creative endeavors. The composition of space form and color reveals certain fluidity; forms of relief blend with those that are on the surface and color often creating inter-mingled relief and flat surfaces (Lochan, 2001).

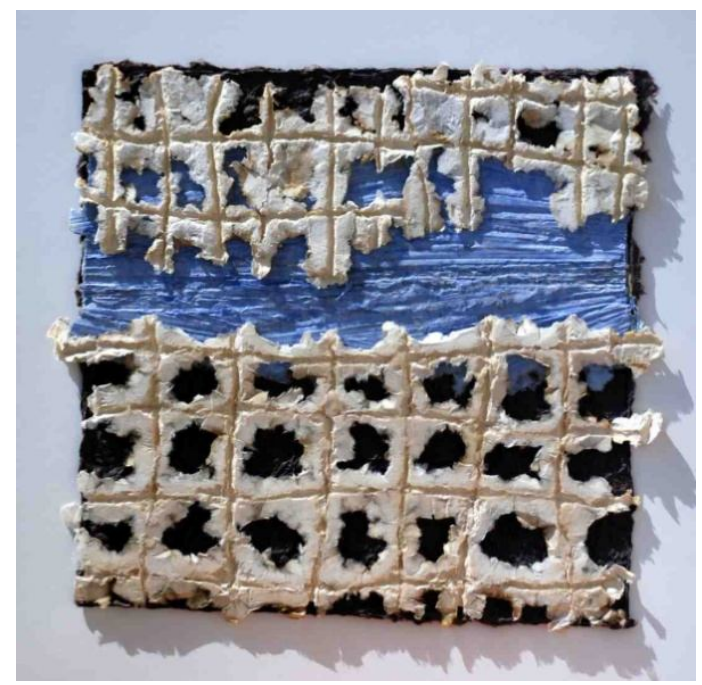

Figure 16: Ingrid Pitzer, Monsoon, Cast paper, 20"x 21", 2014, Retrieved on 16 May 2017 from http://www.artheritagegallery.com/work_for_sale/p_5661

Ingrid Pitzer, born in Siegen, Germany, trained in Sculpture at the University of Arts, Berlin, now living and working in India, specializes in paper reliefs and paper sculptures. Pitzer is technically sound and clear about the type of results occurring in juxtaposing variations of colors and textural quality of pulps; her minimal and sensible approaches of articulation give a wider 
41 | Embossment and its significance approach to practicing Contemporary Art

range of aesthetic perception to her works. Deviating from becoming a conventional sculptor, working in non-perishable mediums like stone, bronze, fiber, etc., Ingrid has carved out a niche for herself in contemporary art with her original and impeccably crafted paper artworks. Further, through the use of this unusual material art history could benefit new discourses on fragility, vulnerability, effect, and sensitivity (Gallery Sumukha, 2018)

Pitzer says "Paper is not as fragile as we imagine, and it never acts against its' own nature." The challenge is to be as artistic as possible and to make out of a very ordinary medium, an interesting piece of art which can evoke a new sensitivity (Art Heritage, 2017).

The study on printmaking predominantly dwelt on its history and technical grounds by focusing on key categories of relief-viscosity, calligraphy, metal embossing, paper pulp, and sculpture creation. This paper has exemplified artist's content and contextual juxtaposition from their works within the context of various scopes of embossments in visual arts. Individual artists have used embossing medium for artistic practice by utilizing symbolism, philosophy and visual language in embossing practices. However, an artist's reinterpretation and the paradigm shift from traditions into more demanding conceptual and aesthetical concerns; these approaches accommodate new dimension to the definition of visual arts.

\section{Acknowledgment}

Much of the ideas of this paper are deeply rooted in the discussion with Kumar Jasakiya, Department of Fine Arts, Amity University, Noida, India. I am thankful for his inspiration and stimulation.

\section{References:}

Lucie-Smith, Edward. 2003. The Thames E Hudson Dictionary of Art Terms. Thames \& Hudson

Turner, Jane. ed. 1996. The Dictionary of Art.. Grove (An imprint of Oxford University Press)

Design Dynamic Print. 2017. http://www.dynamicprint.co.uk/embossing.html. (accessed 17 March 2017)

McIntosh Embossing. 2017. http://mcintoshemboss.com/Embossing.html (accessed 20 March 2017)

Lalit Kala Contemporary-34. 1987. Lalit Kala Academy: New Delhi, p 51.

Sengupta, Ratnotama. 2006. Krishna's Cosmos: The creativity of an Artist, Sculptor E Teacher. Mapin Publishing, p 87.

Reddy, Krishna. 1988. Intaglio Simultaneous Color Printmaking. State University of New York Press, p 18.

Baala, R. 2018. http://www.timeproofart.com/works.html (accessed 15 March 2018)

Shukla, Prayag. 2008. Art Home, Vadodara, Mirrored reality with cognitive images

Chandra, Veena. 2009. Kala Dirgha, International Journal of Visual Art, Vol. 1o, No.19. Page 14

Janakiram, P.V. 1974. Lalit Kala Akademi- monograph, Lalit Kala Contemporary-34. Lalit Kala Academi: New Delhi, p 72

Josef, James. 1987. The New Figurative, Lalit Kala Contemporary-35. Lalit Kala Academi: New Delhi, p 15

Chamberlain, Walter. 1972. The Thames and Hudson Manual of Etching and Engraving. Thames and Hudson Ltd. Page 69

Capon, Robin. 1973. Introducing Abstract Printmaking. Watson -Guptill Publication: New York. Page 83 
42 | The Chitrolekha Journal on Art and Design, Vol. 2, No. 3, 2018

[18] Pillai, Manju P. 2003. Copper extracts: Soliloquies in sheet metal, 2003, Page 340

Ghose. Arun \& Somnath Hore. 1977. Life and Art, Gallery 88, Mumbai

Kimbril, Robert and Geeti Sen. 2006. Paper Houses, Gallery Espace, New Delhi, p 5

Bordewekar, Sandhya. 2013. Art India, Volume XVII issue I, p 57

Asia Art Archive. 2017. http://www.aaa.org.hk/Collection/CollectionOnline/SpecialCollectionItem/15630 (accessed 1o March 2017)

Lochan Rajeev. 2001. Dattatray Aapte. http://dattatrayaapte.com/Rajeev.php. Accessed on 20 March, 2015

Gallery Sumukha. 2018. http://www.sumukha.com/artist.php?artist=333. Accessed on 12 Jan, 2018

Art Heritage. 2017. http://www.artheritagegallery.com/artist/ingrid-pitzer. Accessed on 10 Oct, 2017

Tikendra Kumar Sahu is Assistant Professor, Department of Fine Arts, Amity University, Noida. 